\title{
Applying a Translated Version of the Adolescent Sleep Habits Survey in Russian High School Children with Obesity
}

\author{
Olga Berdina, $\mathrm{PhD}$; Irina Madaeva, $\mathrm{PhD}$, ScD; Svetlana Bolshakova, $\mathrm{PhD}$; MariaTsykunova; \\ Olga Bugun, $\mathrm{PhD}, \mathrm{ScD}$; Liubov Rychkova, Corresponding Member of the RAS \\ Scientific Centre for Family Health and Human Reproduction Problems \\ Irkutsk, the Russian Federation
}

\begin{abstract}
Background: Inadequate sleep duration and sleep patterns have been associated with metabolic and circadian changes that promote obesity. The aim of this study was to applicate a translated version of the Adolescent Sleep Habits Survey to assess sleep habits and schedules in Russian obese adolescents.

Methods and Results: We questioned 87 adolescents aged between 15 and 17 years: 57 with obesity and 30 with a normal weight (NW). In total, some sleep problems were observed in $60.8 \%$ of obese respondents and $28.6 \%$ of NW participants $(P=0.048)$. School-night wake times in obese adolescents did not differ significantly from the same variables in NW adolescents. School-night bedtimes and TST only in an obese sample were later and shorter, respectively, than in NW subjects $(P<0.001$ for both variables). Surprisingly, NW adolescents had a greater bedtime shift than obese peers $(P<0.001)$. Finally, about half of obese respondents reported that they usually eat $(62.7 \%)$ and watch TV $(44.4 \%)$ in bed $(P<0.001$ for both variables compared with controls).

Conclusions: Applying a translated version of ASHS helps assess sleep habits and schedules in Russian adolescents, including obese patients. (International Journal of Biomedicine. 2020;10(1):61-65.)
\end{abstract}

Key Words: adolescents $\bullet$ obesity $\bullet$ sleep-wake rtythm $\bullet$ sleep habits $\bullet$ self-reported survey

\section{Abbreviations}

ASHS, Adolescent Sleep Habits Survey; BMI, body mass index; NW, normal weight; TST, total sleep times

\section{Introduction}

The World Health Organization has identified obesity as a global epidemic with rates of obesity, poor diet, and lack of physical activity rapidly rising in children, adolescents, and adults. ${ }^{(1,2)}$ On average, the prevalence of obesity in school-age children in Europe was $4.9 \%{ }^{(3)}$ According to the results of a multicenter study conducted in Russia, $19.9 \%$ of children and adolescents are overweight, $5 \%$ are obese. ${ }^{(4)}$ Primary or exogenous obesity is a multi-factorial disorder that results

*Corresponding author: Olga Berdina, PhD. The leading researcher of the laboratory of pediatrics and neurophysiology, Scientific Centre for Family Health and Human Reproduction Problems, Irkutsk, Russia.E-mail: goodnight_84@mail.ru from the interaction between an unfavorable socio-cultural environment and polygenic predisposition in an individual. ${ }^{(5)}$ Sleep is a risk factor linked to the development and maintenance of obesity, and it has emerged as a potential target for obesity prevention. ${ }^{(6)}$ It is hypothesized that sleep impacts weight through a variety of biological and behavioral pathways. For example, sleep restriction has been shown to negatively impact energy and glucose metabolism, alter appetitive hormones, and allow for more time to engage in obesogenic behaviors (e.g., television watching, poor diet choices). ${ }^{(7)}$

It is known that during adolescence physiological sleep patterns and psychosocial influences on sleep change. Some studies show that adolescents, compared to adults, have shorter sleep durations, later bedtimes, and greater discrepancies between weekday and weekend sleep schedules. ${ }^{(8,9)}$ Regular 
insufficient sleep and excessive daytime sleepiness are serious epidemics among adolescents. In several studies with large samples of adolescents, researchers reported that from $45 \%$ to $80 \%$ of adolescents experience insufficient sleep on school nights. ${ }^{(10-12)}$ Thereby, adolescents may be particularly vulnerable to sleep-related changes in their weight. Most research on sleep and obesity in adolescents has focused on the associations between sleep duration and sleep quality. Recent studies suggest that patterns of sleep, in addition to sleep duration and quality, may be related to the weight status and may provide a more comprehensive picture of the relationship between BMI and sleep. ${ }^{(13)}$ Specifically, later bedtimes show positive relationships with obesity and negative relationships with physical activity and fruit and vegetable consumption in children and adolescents. ${ }^{(14-16)}$ Furthermore, discrepancies between weekday and weekend bedtimes(bedtime shift) may dysregulate circadian rhythms, as the circadian system is slow to adapt to rapid shifts in sleep, which can then influence metabolic processes. ${ }^{(17)}$ So, a combination of factors, including circadian phase delay, reduced sleep pressure, early school start times, caffeine use, electronic media usage, modern lifestyles, and social obligations, has minimized the opportunities for adolescents to obtain adequate sleep and thus has increased the risk of obesity.

The subjective assessment of sleep patterns is widely performed in sleep studies. From the earliest times of epidemiology, questionnaires have been used as a basic instrument for data collecting and screening. ${ }^{(18)}$ Self-reported sleeping habit questionnaires are relatively easy to utilize and continue to be the most requested and widely used method. Respondents usually estimate bedtimes, waking times, hours of sleep, sleep habits, sleepiness, and so on. Most of the questionnaires are valid only for pre-pubertal children or adults, but not adolescents. Wolfson and colleagues (1998) successfully attempted to study sleep and waking behaviors in American high school children using the Sleep Habits Survey and showed that most of the adolescents surveyed do not get enough sleep, and their sleep loss interferes with daytime functioning. ${ }^{(19)}$ In 2003, the above-mentioned authors examined the validity of this questionnaire through a comparison of retrospective survey descriptions of usual school- and weekend-night sleep habits with diary-reported sleep patterns and actigraphically estimated sleep behaviors. Their results support the validity of the Sleep Habits Survey estimates in comparison with sleep diary and actigraphy in high school children. ${ }^{(20)}$ Sung (2011) used the Youth Sleep Habits Survey to assess self-reported sleep duration in obese adolescents. ${ }^{(21)}$ Shahid and colleagues described this questionnaire as ASHS for schoolchildren in grades 4 through 12, developed in 2009 as part of Pediatric Sleep Disorders Program. ${ }^{(22,23)}$ However, the administration of this sleep questionnaire for Russian obese adolescents is not established.

Based on the description above, the problem of this research is that sleep is a risk factor linked to the development of obesity, and many adolescents report sleep-wake schedules that involve late bedtimes and short sleep in self-report survey questionnaires.

The purpose of this study was to translate and applicate the ASHS to assess sleep habits and schedules in Russian adolescents with obesity.

\section{Materials and Methods}

We conducted a cross-sectional study, which involved 57 obese patients (Group 1) aged 15 to 17 years, who were referred to the Clinic of the Scientific Center for Family Health and Human Reproduction in 2019. Thirty age- and sexmatched adolescents with NW were included in the control group (Group 2).

Study inclusion criteria were the 15-17 year age range; BMI Z-score $>2$ for age and sex for Group 1 and BMI Z-score from -1 to +1 for age and sex for Group 2; and a signed informed consent form. The study exclusion criterion was unwillingness to participate in this study.

The program of the study included a general medical examination with anthropometric measurements, questioning and statistical analysis.

Anthropometric parameters of adolescents were assessed once when they were included in the study. Body mass index (BMI, $\mathrm{kg} / \mathrm{m}^{2}$ ) was calculated. The growth and weight parameters of the adolescents were evaluated using the reference values of the $\mathrm{WHO}$ and the AnthroPlus calculator (2009). The nutritional status was determined by the values of the Z-score. ${ }^{(24)}$

To fulfill the purpose of this study, the sleeping habits were evaluated subjectively, using a questionnaire-the Russian version of the ASHS. This is a structured survey featuring both open-ended and multiple-choice questions, which allows for the collection of demographic details, familial and medical histories, and information regarding sleep habits, schedules, and behaviors. Two versions of the self-reported survey were used (differing only in their mention of either male- or female-related developmental milestones). Each version is a pencil-and-paper instrument, consisting of between 61 (for boys) and 62 (for girls) questions and should require between 20 and $30 \mathrm{~min}$ for completion. Research assistants met with the participants once upon admission to the hospital. The survey items queried adolescents about usual sleeping and waking behaviors (sleep problems, sleep habits, sleep history, daytime sleepiness and sleep/wake rhythms) over the last two weeks, which is a typical interval for pointassessment sleep habit surveys. This article examines the following the ASHS variables: (1) for sleep problems ("Do you have sleep problems(s)?" answered as "Yes" or "No"; (2) for usual sleep habits (school and weekend nights separately): (a) ASHS bedtime: usual bedtime ("What time do you usually go to bed on school days?" answered as one specific time, such as 10:30 p.m.); (b) ASHS wake time: usual wake time ("What time do you usually wake up on weekends?" answered as one time, such as 9:30 a.m.); (c) ASHS TST: usual total sleep time ("Figure out how long you usually sleep on a school night and fill it in here," answered as specific hours and minutes such as 7 hours, 30 minutes); (d) ASHS latency: usual sleep latency ("On weekends, after you go to bed at night, about how long does it usually take you to fall asleep?" answered as specific minutes, such as 20 minutes; if longer than one 
hour, change to minutes); (3) for possible sleep habits: (a) ASHS activities: possible activities in bed ("How often have you done any of the following activities in bed?: read, watch TV, eat, do schoolwork, worry" answered as "Every night," "Several times," "Twice," "Once" or "Never"; (b) ASHS falling asleep: possible activities if difficulty falling asleep ("When you have difficulty falling asleep or getting back to sleep, what do you do?: try to get to sleep, do something in bed, get up and watch TV, get up and drink warm milk/water/ tea/coffee, other" checked as "All that apply").

The study was conducted in accordance with ethical principles of the WMA Declaration of Helsinki (1964, ed. 2013) and approved by the Ethics Committee of Scientific Centre for Family Health and Human Reproduction Problems. Written informed consent was obtained from the patient/ parent/guardian/ relative of each patient.

Statistical analysis was performed using the Statistica 6.1 software package (Stat-Soft Inc., USA). The normality of distribution of continuous variables was tested by the Kolmogorov-Smirnov test with the Lilliefors correction and Shapiro-Wilk test. Baseline characteristics were summarized as frequencies and percentages for categorical variables and as mean \pm standard deviation (SD) for continuous variables. For data with normal distribution, inter-group comparisons were performed using Student's t-test. Mann-Whitney U test was used to compare means of variables not normally distributed. Group comparisons with respect to categorical variables were performed using chi-square tests or, alternatively, Fisher's exact test. A probability value of $P<0.05$ was considered statistically significant.

\section{Results and Discussion}

Characteristics and response to the ASHS for the participants were analyzed. Comparisons for age, sex, zBMI and survey variables (for usual sleep habits) between participant groups are shown in Table1. Adolescents of Group 1 had a mean age of 16.2 years with an average zBMI of 2.56, whereas Group 2 adolescents $(\mathrm{n}=30)$ had a mean age of 16.1 years $(P>0.05)$ with an average zBMI of $0.7(P<0.05)$. The proportion of girls in the study was $22.8 \%$ and $20.1 \%$ for Group 1 and Group 2, respectively ( $P>0.05)$.

School-night wake times in Group 1 did not differ significantly from the same variables in Group 2. On average, estimates were within 5 minutes, and all participants reported waking up at about 7:10 a.m. Conversely, survey-reported school-night bedtimes in Group 1 were significantly later (on average 60 minutes) and TST significantly less (on overage 65 minutes) than in Group 2 ( $P<0.001$ for both variables). However, participants of Group 1 reported a trend toward longer times falling asleep versus adolescents of Group 2. Finally, survey-reported weekend bedtimes, TST and wake times in Group 1 did not differ significantly from the same variables in Group 2.

Next, we carried out a comparative analysis of the remaining questionnaire data and obtained the following results: About $60.8 \%$ of respondents in Group 1 answered that they have some sleep problems, compared with $28.6 \%$ in Group $2(P=0.048)$. According to the self-assessment of possible sleep habits in the last two weeks, in the section "ASHS activities," $24.3 \%$ of respondents noted their activities in bed as "Read" in Group 1 and $25.1 \%$ in Group $2(P>0.05)$; as "Watched TV" $37.4 \%$ and $31.1 \%(P>0.05)$, respectively; as "Ate" $54.8 \%$ in Group 1 and $27.1 \%$ in Group $2(P<0.05)$; as "Did schoolwork" $16.9 \%$ and $17.1 \%$, respectively $(P>0.05)$; as "Worried" $24.6 \%$ in Group 1 and 19.8\% in Group $2(P>0.05)$. Furthermore, more than half of Group 1 adolescents (62.7\%) answered "ate in the bed" as "Every day/night" compared with $28.3 \%$ of Group 2 respondents ( $P=0.034$ ); and $44.4 \%$ of participants in Group 1 answered "watched TV in the bed" as "Every night" compared to $18.5 \%$ participants in Group $2(P=0.048)$. In section "ASHS falling asleep" respondents noted when they had difficulty falling asleep: $42.8 \%$ of Group 1 respondents and $71.8 \%$ of Group 2 respondents "stayed in bed and tried to get to sleep" ( $P=0.047) ; 33 \%$ vs. $18.1 \%$ $(P=0.63)$, respectively, "Did something in bed"(e.g., read, ate or watched TV); $9.1 \%$ of Group 1 adolescents and $10.1 \%$ of Group 2 participants "got up and watched TV" $(P=0.93)$; also, $15.1 \%$ of Group 1 respondents answered that they "got up and drunk warm milk/water/tea/coffee."

Table 1.

Comparisons for age, sex, zBMI and ASHS assessment between participant groups

\begin{tabular}{|l|c|c|}
\hline \multicolumn{1}{|c|}{ Variable } & Group 1 & Group 2 \\
\hline Age, y & $16.3 \pm 0.5$ & $16.1 \pm 0.3$ \\
\hline Gender (M/F) & $44(77.2) / 13(22.8)$ & $24(80) / 6(20)$ \\
\hline BMI, kg/m2 & $34.9 \pm 2.3^{*}$ & $19.8 \pm 1.9$ \\
\hline zBMI & $2.4 \pm 0.4^{*}$ & $0.7 \pm 0.2$ \\
\hline School-night TST, min & $450.2(82.4)^{*}$ & $515.1(45.8)$ \\
\hline Weekend-night TST, min & $612.7(124.1)$ & $618.5(83.2)$ \\
\hline School-night bedtime^ & $23: 07(1: 22)^{*}$ & $22: 05(45)$ \\
\hline School-night wake time^ & $7: 12(50)$ & $7: 07(42)$ \\
\hline Weekend-night bedtime^ & $23: 52(1: 34)$ & $23: 47(53)$ \\
\hline Weekend-night wake time^ & $10: 05(1: 31)$ & $10: 15(1: 23)$ \\
\hline Bedtime shift^ & $53(1: 17)$ & $1: 47(52)^{*}$ \\
\hline $\begin{array}{l}\text { School-night sleep latency, } \\
\text { min }\end{array}$ & $17(9.2)$ & $13.6(8.4)$ \\
\hline $\begin{array}{l}\text { Weekend-night sleep latency, } \\
\text { min }\end{array}$ & $20.1(15.7)$ & $15.7(10.1)$ \\
\hline
\end{tabular}

${ }^{\wedge}$ Bedtimes, wake times and bedtime shift are expressed in 24-h clock; zBMI, body mass index-for-age $z$-score; $* P<0.05$

Our study found that adolescents with obesity have later school-night bedtimes, trend toward greater sleep latency and significantly shorter weekday sleep duration versus a NW peer. Of note is that as student sleep opportunities are curtailed most in the morning so as not to be late for school, the time that adolescents go to bed is a key determinant of how much sleep they obtain. ${ }^{(25)}$ Surprisingly, NW adolescents had a greater bedtime shift than obese peers $(P<0.001)$; that result differs from the results of Hayes et al. (2018), who found the same schedule pattern in adolescents with overweight and obesity. ${ }^{(26)}$ 
In that study, 186 respondents aged from 12 to 17 years reported typical sleep and wake times on weekdays and weekends using the Pittsburgh Sleep Quality Index questionnaire. In contrast to our results, that study found that zBMI was not related to weekday bedtimes, but significantly related to weekend bedtimes as well as bedtime shift in obese adolescents. However, shorter school-night TST in obese participants confirms the availability of relationships between sleep duration and overweight, which have been reported in the majority of the extant literature. ${ }^{(7,14,27,28)}$ In the current study, we found that self-reported average sleep duration on the weekdays in an obese group was not within the recommended $8-10$, hours, in contrast to the control group. ${ }^{(29,30)}$ Specifically, only $14 \%$ of the obese adolescents reported more than 8 hours of sleep on school nights compared with $83 \%$ of NW adolescents.

It is argued that later bedtimes and sleep deficit occur due to the confluence of psychosocial and biological factors of adolescent development. ${ }^{(31)}$ Much work has been done to determine how the types of activities adolescents engage in immediately before sleep impact subsequent sleep. ${ }^{(32,33)}$ As the current study shows, about half of obese respondents reported that they "ate and watched TV in bed every night" in the last two weeks, which significantly differed from NW adolescents. The same behavioral patterns are also an important risk factor for obesity and are significantly associated with the severity of overweight. Many studies have found that screen time is adversely associated with both sleep outcomes (34) and obesity. ${ }^{(35)}$ A previous study in children and adolescents with overweight and obesity showed that later bedtimes were related to increased daily high calorie food intake and screen time. ${ }^{(36)}$

The present study adds additional evidence and extends the current literature on the association of sleep habits with weight in adolescents with obesity. It showed that about two thirds of obese respondents had some sleep problems compared with one third of controls $(P<0.05)$. Despite some limitations of the study, such as small sample size and selfreported survey estimates of sleep patterns only, we found certain differences between usual school- and weekendnight sleep habits in obese and NW participants, which allow justifying the possibility of using ASHS to assess sleep habits and schedules in Russian adolescents, including those with obesity. However, despite the results, future studies should use objective measures of sleep (polysomnography) and consider accurate measurement, particularly as self-reported sleep duration tends to be overestimated.

\section{Competing Interests}

The authors declare that they have no competing interests.

\section{References}

1. World Health Organization. World health statistics 2006. Geneva, Switzerland: WHO Press; 2006:1-80.

2. Wang Y, Lobstein T. Worldwide trends in childhood overweight and obesity. Int J Pediatr Obes. 2011;1(1):11-25. doi: $10.1080 / 17477160600586747$

3. Olaya B, Moneta MV, Pez O, Bitfoi A, Carta MG, Eke C, et al. Country-level and individual correlates of overweight and obesity among primary school children: a cross-sectional study in seven European countries. BMC Public Health. 2015;15:475. doi: 10.1186/s12889-015-1809-z.

4. Tutelyan VA, Baturin AK, Kon' IYa, Martinchik AN, Uglitskikh AK, Korosteleva MM, et al. [Prevalence of overweight and obesity in child population of Russia: multicenter study]. Pediatrics Journal named after G.N. Speransky. 2014;93(5):28-31. [Article in Russian].

5. Kolesnikova L, Dzyatkovskaya E, Rychkova L, Polyakov V. New approaches to identifying children of psychosomatic disorders risk group. Procedia - Social and Behavioral Sciences. 2015;214:882-889. doi: 10.1016/j.sbspro.2015.11.745.

6. Madaeva I, Berdina O, Rychkova L. OSA and obesity in adolescents: sleep features. Chest. 2019;155(4):309.

7. Hart CN, Cairns A, Jelalian E. Sleep and obesity in children and adolescents. Pediatr Clin North Am. 2011;58(3):715-33. doi: 10.1016/j.pcl.2011.03.007.

8. Carskadon MA, Acebo C, Richardson GS, Tate BA, Seifer R. An approach to studying circadian rhythms of adolescent humans. J Biol Rhythm. 1997;12(3):278-89.

9. Hagenauer MH, Lee TM. The neuroendocrine control of the circadian system: adolescent chronotype. Front Neuroendocrinol. 2012;33(3):211-29. doi: 10.1016/j. yfrne.2012.04.003.

10. Gradisar M, Gardner G, Dohnt H. Recent worldwide sleep patterns and problems during adolescence: a review and metaanalysis of age, region, and sleep. Sleep Med. 2011;12(2):1108. doi: 10.1016/j.sleep.2010.11.008.

11. Keyes KM, Maslowsky J, Hamilton A, Schulenberg J. The great sleep recession: changes in sleep duration among US adolescents 1991-2012. Pediatrics. 2015;135(3):460-468. doi: 10.1542/peds.2014-2707.

12. Tonetti L, Fabbri M, Natale V. Sex difference in sleep-time preference and sleep need: a cross-sectional survey among Italian pre-adolescents, adolescents, and adults. Chronobiol Int. 2008;25(5):745-59. doi: 10.1080/07420520802394191.

13. Miller AL, Lumeng JC, LeBourgeois MK. Sleep patterns and obesity in childhood. Curr Opin Endocrinol Diabetes Obes. 2015;22(1):41-7. doi: 10.1097/MED.0000000000000125.

14. Chaput JP. Sleep patterns, diet quality and energy balance. Physiol Behav. 2014;134:86-91. doi: 10.1016/j. physbeh.2013.09.006.

15. Chung K-F, Kan KK-K, Yeung W-F. Sleep duration, sleep-wake schedule regularity, and body weight in Hong Kong Chinese adolescents. Biol Rhythm Res. 2012;44:169179. doi: 10.1080/09291016.2012.656247.

16. Golley RK, Maher CA, Matricciani L, Olds TS. Sleep duration or bedtime? Exploring the association between sleep timing behaviour, diet and BMI in children and adolescents. Int J Obes (Lond). 2013;37(4):546-51. doi: 10.1038/ijo.2012.212. 17. Dahl RE, Lewin DS. Pathways to adolescent health sleep regulation and behavior. J Adolesc Health. 2002;31(6 Suppl):175-84.

18. Owens JA, Spirito A, McGuinn M. The Children's Sleep Habits Questionnaire (CSHQ): psychometric properties of a survey instrument for school-aged children. Sleep. 2000;23(8):1043-51.

19. Wolfson AR, Carskadon MA. Sleep schedules and daytime functioning in adolescents. Child Develop. 1998;69(4):875-87. 20. Wolfson AR, Carskadon MA, Acebo C, Seifer R, Fallone 
G, Labyak S, et al. Evidence for the validity of a sleep habits survey for adolescents. Sleep. 2003;26(2):213-6.

21. Sung V, Beebe DW, VanDyke R, Fenchel MC, Crimmins NA, Kirk S, et al. Does sleep duration predict metabolic risk in American obese adolescents attending tertiary services? A cross-sectional study. Sleep. 2011;34(7):891-8. doi: 10.5665/ SLEEP.1122.

22. Shahid A. STOP, THAT and One Hundred Other Sleep Scales. Springer Science+Business Media; 2011:1-44.

23. KIDZZZSLEEP Pediatric Sleep Disorders Program. (April 3, 2009). Clinical tools. Retrieved. June 17, 2009, [Electronic resource]. http://www.kidzzzsleep.org/clinicaltools.

24. Obesity and overweight. Report of a WHO. 2015, [Electronic resource]. http://www.who.int/mediacentre/ factsheets/fs311/en.

25. Short MA, Gradisar M, Lack LC, Wright HR, Dewald JF, Wolfson AR, et al. A cross-cultural comparison of sleep duration between US And Australian adolescents: the effect of school start time, parent-set bedtimes, and extracurricular load. Health Educ Behav. 2013;40(3):323-30. doi: 10.1177/1090198112451266.

26. Hayes JF, Balantekin KN, Altman M, Wilfley DE, Taylor CB, Williams J. Sleep Patterns and Quality Are Associated with Severity of Obesity and Weight-Related Behaviors in Adolescents with Overweight and Obesity. Child Obes. 2018;14(1):11-17. doi: 10.1089/chi.2017.0148.

27. Beebe DW, Lewin D, Zeller M, McCabe M, MacLeod K, Daniels SR, et al. Sleep in overweight adolescents: Shorter sleep, poorer sleep quality, sleepiness, and sleep disordered breathing. J Pediatr Psychol. 2007;32(1):69-79.

28. Garaulet M, Ortega FB, Ruiz JR, Rey-Lopez JP, Beghin L, Manios Y, et al. Short sleep duration is associated with increased obesity markers in European adolescents: Effect of physical activity and dietary habits. The HELENA study. Int J
Obes (Lond). 2011;35(10):1308-17. doi: 10.1038/ijo.2011.149. 29. Paruthi S, Brooks LJ, D’Ambrosio C, Hall WA, Kotagal S, Lloyd RM, et al. Recommended amount of sleep for pediatric populations: A consensus statement of the American Academy of Sleep Medicine. J Clin Sleep Med. 2016;12(6):785-6. doi: $10.5664 / \mathrm{jcsm} .5866$.

30. Short MA, Weber N, Reynolds C, Coussens S, Carskadon MA. Estimating Adolescent Sleep Need Using DoseResponse Modelling. Sleep. 2018;41(4):1-41. doi: 10.1093/ sleep/zsy011.

31. Bartel KA, Gradisar M, Williamson P. Protective and risk factors for adolescent sleep: a meta-analytic review. Sleep Med Rev. 2015;21:72-85. doi: 10.1016/j.smrv.2014.08.002.

32. Cain N, Gradisar M. Electronic media use and sleep in school-aged children and adolescents: A review. Sleep Med. 2010;11(8):735-42. doi: 10.1016/j.sleep.2010.02.006.

33. Hysing M, Pallesen S, Stormark KM, Jakobsen R, Lundervold AJ, Sivertsen B. Sleep and use of electronic devices in adolescence: results from a large populationbased study. BMJ Open. 2015;5(1):e006748. doi: 10.1136/ bmjopen-2014-006748.

34. Hale L, Guan S. Screen time and sleep among school-aged children and adolescents: A systematic literature review. Sleep Med Rev. 2015;21:50-58. doi: 10.1016/j.smrv.2014.07.007.

35. Calamaro CJ, Park S, Mason T, Marcus CL, Weaver TE, Pack A, et al. Shortened sleep duration does not predict obesity in adolescents. J Sleep Res. 2010;19(4):559-66. doi: 10.1111/j.1365-2869.2010.00840.x.

36. Adamo KB, Wilson S, Belanger K, Chaput J-P. Later bedtime is associated with greater daily energy intake and screen time in obese adolescents independent of sleep duration. In: Vash PD (ed), Complexity of Adolescent Obesity: Causes, Correlates, and Consequences. Oakville, Canada: Apple Academic Press; 2015:37-50. 